\title{
Tourism and Sustainability in India - Exploring Sustainability of Goa Tourism from the Perspective of Local Community
}

\author{
T. Venugopalan
}

\section{ABSTRACT}

\begin{abstract}
This research paper empirically examines the economic, environmental, and social sustainability of Goa tourism from the perspective of the local community. A structured questionnaire survey was conducted among the local community across Goa, the model tourist destination of India. This research has used descriptive statistics for examining the environmental, economic, and social sustainability of tourist destinations of Goa. The factor analysis has been used for identifying the factors that determine the sustainability of Goa tourism from the perspective of the local community. The research findings prove that tourism development is ensuring the environmental and economic sustainability of tourist destinations of Goa. However, the findings on social sustainability indicators prove that tourism is exerting huge pressure on Goa's society. The factor analysis discloses that the factors such as resource exploitation, resource management, socioeconomic empowerment, economic and governance systems, destination empowerment, poverty eradication, and tourism governance, influence the sustainability of tourism in Goa.
\end{abstract}

Keywords: Sustainable development, Tourism governance, Destination management, Leakage, Empowerment, Poverty eradication.

\section{INTRODUCTION}

Tourism is recognized as an engine of socio-economic growth in developed, developing and underdeveloped countries. It facilitates infrastructure development and alleviation of poverty, contributes precious foreign exchange, and generates employment opportunities. However, indiscriminate mass tourism brought about catastrophic repercussions on the ecology, economy, and society. The large influx of tourists and the concentration of tourist activities in certain destinations have created insurmountable stress and strain on both resources and the local community [1], [2]. Sustainable tourism has emerged as the most comprehensive approach to mitigate the adverse impacts of tourism and to achieve sustainable development in tourist destinations. Sustainable tourism has been defined as "tourism development that meets the needs of present tourists and host regions while protecting and enhancing opportunities for the future" [3]. Sustainable tourism considers the present and future environmental, economic, and socio-cultural effects by addressing the needs and requirements of tourists, the tourism industry, the environment, and the host communities.

Tourism is a significant segment of the Indian economy, which contributes immensely to the socio-economic development of millions of rural people. However, the lopsided planning and haphazard implementation of tourism plans have brought a plethora of problems and issues, which challenge the economic, social, and environmental existence of the tourist destinations. literature immensely.

\author{
Submitted : April 14, 2021 \\ Published : May 05, 2021 \\ ISSN: $2507-1076$ \\ DOI: $10.24018 /$ ejbmr.2021.6.3.852 \\ Dr T. Venugopalan * \\ Assistant Professor, Department of \\ Commerce, Sri Guru Tegh Bahadur Khalsa \\ College, University of Delhi, India. \\ (e-mail: venugopalan @ sgtbkhalsa.du.ac.in)
}

The benefits of tourism development have been redistributed among the tourism business operators, promoters of hotels and restaurants, and big corporations at the cost of local communities [1], [2], [5], [8]. Hence, the central government and state governments have acknowledged sustainability as the fundamental principle of development processes and accomplishing sustainable development through sustainable tourism is identified as the major objective of tourism development in India. However, there have been limited studies conducted to empirically evaluate the impacts of tourism on the environment, economy, and society, and the efficacy of the policies and programmes of the Government in achieving sustainability of tourist destinations. Hence, this research paper has identified Goa - a model of Indian tourism, for studying various dimensions of tourism development and implementation of tourism policies and programs. This research paper evaluates the sustainability of Goa tourism empirically from the perspective of local communities. Therefore, the research findings may not only help the tourism decision-makers while designing and implementing tourism policies and programmes but also contribute to the tourism management

The main objective of the research paper is to study the impacts of tourism on the economy, environment, and society of Goa from the perspective of the local community. It also attempts to identify the factors contributing to the economic, environmental, and socio-cultural sustainability of the tourist destinations of Goa. Descriptive statistics and factor analysis 
have been used for examining the sustainability of Goa tourism.

The descriptive statistics prove that tourism development in Goa is ensuring the economic and environmental sustainability of tourist destinations. However, the research findings do not support the hypothesis that tourism leads to socio-cultural sustainability of tourist destinations. The factor analysis discloses that the factors such as resource exploitation, resource management, socio-economic empowerment, economic and governance systems, destination empowerment, poverty eradication, and tourism governance, influence the sustainability of tourism in Goa.

This paper is organized as follows. Section 2, review of literature provides a discussion on the previous researches on the impacts of tourism on Goa. Section 3, research methodology describes the sample, methods, and materials adopted for measuring the variables and analysing the data. Section 4, data analysis examines the data using descriptive statistics and exploratory factor analysis. Section 5, Conclusion, concludes the research paper and discusses the limitations and future directions for the research.

\section{REVIEW OF LITERATURE}

Tourism generates both positive as well as negative impacts on the environment, economy, and society of Goa [4]. Tourism serves as a major segment of Goa's economy, which provides many economic benefits and changes the destiny of millions of people from the disadvantaged sections of the society. Tourism reduces widespread poverty by boosting national income, generating employment, earning foreign currency, ensuring regional development, and promoting handicrafts, etc. There is also leakage effect of tourism revenue in Goa through either import of construction materials and equipment or consumer goods from other states. Leakage of income could have been avoided if the tourism industry had a locally sourced food supply. Despite having the active involvement of local people in tourism development, the gains derived from tourism are not substantial. The large hotels, restaurants, and tourism developers are extracting the economic benefits leaving the host community to swallow the social and environmental cost [5].

The seasonality of tourism activities in Goa makes the tourism resources remain unutilized or underutilized during slack seasons. Conversely, during peak seasons, the industry has to overstretch its infrastructure to meet the demand as the tourist population breaches the carrying capacity and surpasses the local population, which exerts huge pressure on tourism resources [5]. Tourism has changed the nature and structure of occupations of the local community. Traditional systems of cultivation and fishing have dwindled, and agriculture has become a part-time activity for the workers. The unskilled workers of the tourism industry, who experience the sharpest downswing in income and employment during slack seasons, always become a social cost of the industry and state government [1], [5]-[7]. Occupation in the villages has become tourist-oriented because the local communities have shifted themselves from traditional occupations to tourism-related activities [4]. Tourism has been the reason for the excessive increase in the cost of living in popular tourist destinations. The rising prices of goods and services and the increasing cost of housing and properties are big disadvantages to the local community [8].

The rapid and uncontrolled tourism development caused irreparable damages to the environment because the tourism industry prefers to maximize its economic interests at the cost of the environment. The tourism infrastructure is often developed on the most beautiful landscapes, which not only destroy the environment but also deplete both the natural and cultural resources for both present and future generations [5]. Over-utilized waste disposal systems, dumping of solid and liquid wastes, limited enforcement of deterrent measures against beach pollution, water bodies, and ecologically sensitive areas, and violation of coastal zone regulation are some of the pressing challenges of Goa tourism [9].

Mass tourism in Goa has exceeded the carrying capacity and the water resource in many coastal areas is stressed due to tourism-related activities. Unregulated coastal tourism and water sports have damaged the marine ecosystems irretrievably [5], [4], [11], [10]. The rapid tourism development and urbanization are changing the structure and character of the colonial towns of Goa [12]. Tourism puts pressure on transportation infrastructure and the existing transportation infrastructure is inadequate to meet the travel requirements of both tourists and the host community. Waste generation and littering have become major concerns. The existing waste management system is inadequate, and the local administrators have been struggling to manage the mounting waste generated by tourism. There is no mechanism existing in Goa for managing and recycling huge quantities of liquid and solid waste generated by the tourism industry [11]. However, recently the government has taken initiatives to establish waste recycling plants in South Goa, and Central Goa [9].

Tourism has brought about positive impacts on Goa's society. Tourism protects and conserves both social and cultural heritage. The infrastructure facilities and recreational activities developed for tourism have benefited the local communities. Tourism has also empowered females financially through increased job opportunities. The household decision-making power has been shifted away from males to females [13]. Tourism has transformed traditional Goa's society, which is profoundly influenced by western culture. Tourism has led to the commercialization of art and culture, which gradually destroyed the purity, and originality of the unique traditions. Tourist destinations have become the hub of money laundering, drugs, prostitution, and trafficking in women and children [5], [13]. Tourism is also responsible for the displacement of traditional coastal communities and wrecked their homes and livelihood, cultural heritage, and sacred religious sites, [5]. Tourism brings together people having different cultures, languages, lifestyles, and religions, which lead to cultural clashes [4], [5].

Thus, the review of the literature establishes that tourism development has been exerting tremendous pressure on the environment, economy, and society of Goa. The government of India and the state government of Goa have introduced and implemented innumerable plans and programmes for alleviating the negative impacts of tourism and enhancing the sustainability of the environment, economy and society. 


\section{RESEARCH METHODOLOGY}

The focus of the research paper has been on three aspects of sustainable tourism development: environmental sustainability, economic sustainability, and socio-cultural sustainability. Primary research has been undertaken for studying the sustainability of tourism through the questionnaire survey conducted at different tourist destinations across Goa. UNEP and WTO [14] provide a comprehensive framework for measuring sustainability in "Making Tourism More Sustainable: A Guide for Policy Makers". Based on these guidelines, a structured questionnaire was prepared by incorporating sustainability indicators. The questionnaire was composed of 40 statements representing 40 sustainable indicators on the economy, environment, society and culture, and tourism governance [17]. The 5-point Likert scale, a non-comparative scaling technique has been used for designing the questionnaire. This research paper has used both judgemental sampling random sampling and the tourist destinations were chosen based on the popularity in the domestic and international tourism market. The questionnaire survey was randomly executed in all selected tourist places. The survey was conducted among the local community of Goa. A data set consisting of the responses of 254 local community members was prepared from the questionnaire survey.

\section{DATA ANALYSIS}

The main aim of this paper is to examine the sustainability of tourism development in Goa and identify the factors, which contribute to the economic, environmental, and sociocultural sustainability of Goa from the perspective of the local community, using descriptive statistics and factor analysis.

\section{A. Data Structure Analysis}

The questionnaire survey was executed randomly among the local community at various tourist destinations and generated a database consisting of 254 respondents. The data collected from 254 local people represented 63\% males and $37 \%$ females. The sample is comprised of $15 \%$ people from the age group of $18-25,42 \%$ from the age group of $25-40$, $32 \%$ from the age group of $40-60$, and $11 \%$ from above 60 years of age. The educational background of participants discloses that $27 \%$ of people were below matriculation, $23 \%$ were undergraduates, $32 \%$ were graduates, and $18 \%$ had done post-graduation. The data also show that respondents with income levels below Rs. 10,000 represent 10\%, income between Rs. 10,000-20,000 represent 20\% and income between Rs. 20,000-30,000 represent 40\% and above Rs. 50,000 represent $30 \%$ of the total number of local communities.

\section{B. Descriptive Statistics}

Descriptive statistics like, mean and standard deviation have been used for examining the perception of the local community about the sustainability of tourism development in Goa. Table 1 provides the descriptive statistics for various sustainability indicators, economic, social, and environmental sustainability, which are the pillars of sustainable development.
Table I discloses the descriptive statistics about the perception of the local community about the tourism governance, economic, environmental, and socio-cultural sustainability of Goa tourism in Goa.

Tourism Governance: Table I discloses that the respondents have awarded a mean score of 3.37 to Tourism Policy. The mean score on Tourism Policy explains that the tourism plans and programmes formulated and implemented by Goa Government are positively contributing to the sustainable development of the destinations. The Local Community Engagement has scored a mean value of 3.10, which reveals that the government is integrating and engaging the local community in the formulation and implementation of tourism plans and policies. The mean value of Local Government Involvement (3.26) reveals that the local government is actively involved in the formulation and implementation of tourism plans, policies, and programmes. The local community awarded an average score of 3.04 to the Legal System, which provides weak support for the argument that there is an efficient and effective legal system to deal with the violation of rules and regulations regarding tourism. The Safety and Security have scored a moderate mean value of 3.19 , which establishes that in all tourist destinations of Goa, the government is providing safety and security to the tourists, local community, and tourism business operators. The mean value of Managed Tourist Destinations (3.37) reveals that tourism is giving importance to the protection and conservation of the natural, social, and cultural heritage of Goa. Thus, the descriptive statistics on Tourism Governance strongly support the empirical hypothesis that tourism governance measures are directly contributing to the sustainability of tourist destinations.

Economic Sustainability: Table I demonstrates the perception of the local community whether the tourism development brings economic sustainability across the tourist destinations in Goa. The respondents have given a very low score to Equitable Distribution of Income (2.79), which discloses that the revenue generated by tourism is not equitably distributed among the local community. The respondents have awarded a mean score of 3.67 to Employment Generation, which signifies that the majority of the local community perceives tourism as an important segment of an economy that offers employment opportunities directly and indirectly. The residents expressed that there are various government agencies and private institutions, which provide training for Skill Development (3.27) to local community members who want to venture into tourismrelated business activities. The mean score of Poverty Reduction 3.58 shows that tourism is facilitating the eradication of poverty, improvement in the living standard and quality of life of the local people. The mean value of Implementation of Labour Laws (3.06) provides weak support for the argument that the tourism industry has implemented the labour laws and regulations regarding minimum wage and satisfactory working conditions and other amenities. 
TABLE I: DESCRIPTIVE STATISTICS

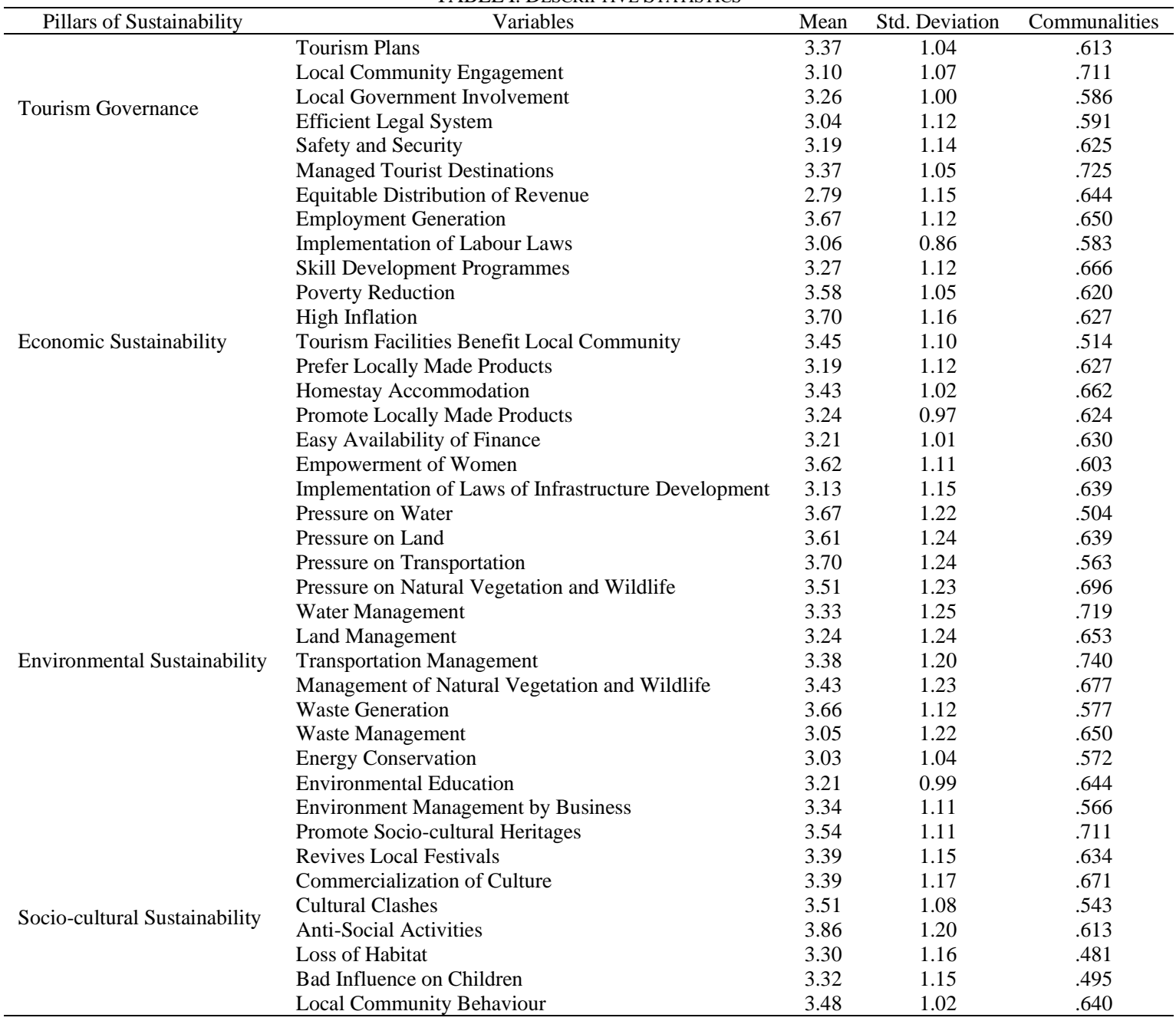

Source: SPSS Output from Primary Survey.

The mean score on Tourism Facilities Benefit Local Community (3.45) shows that the tourism infrastructure and recreational activities developed for entertaining the tourists are also benefitting the local community. Similarly, the local community believes that the tourists Prefer Locally Made Products (3.19). The preference of tourists for locally made products generates huge demand for locally made products and boosts up the local economy, reduces poverty, and empowers the local community.

The local community has assigned a mean score of 3.43 to the Homestay Accommodation. In Goa, the concept of homestay accommodation has been gaining popularity and more and more tourists prefer homestay accommodation that provides additional income to the local community. The tourist destinations experience invariably High Inflation (3.70). The prices of goods and services are exorbitant across the state and that makes the life of the local community miserable. The mean value of Promote Locally Made Products (3.24) reveals that the tourism business operators promote locally made products by maintaining economic linkages with the indigenous producers.

The average score of Easy Availability of Finance (3.21) also establishes that the government is providing various financial and non-financial assistance for setting up tourismrelated business houses to the members of the local community. The average score of Implementation of Laws of Infrastructure Development (3.13) reveals that the government ensures the tourism developers adhere to the laws and regulations related to the infrastructure developments while developing tourism infrastructure and other activities. The mean value for Empowerment of Women (3.62) proves that tourism contributes to the alleviation of poverty and improvement in the quality of life by providing meaningful employment, satisfactory remuneration, and decent working conditions to the members of the local community, especially the disadvantaged groups and women. Thus, the findings on economic sustainability indicators strongly support the research hypothesis that tourism development is directly contributing to the economic sustainability of tourist destinations of Goa.

Environmental Sustainability: The mean value of Pressure on Water (3.67) establishes that the indiscriminate exploitation of water and water resources by the tourism industry creates water scarcity, water contamination, and depletion of groundwater on many beaches. Similarly, the average score on Pressure on Land (3.61) strongly supports the argument that tourism leads to pressure on land resources. The local community has assigned an average score of 3.70 to Pressure on Transportation, which discloses that tourism is exerting much pressure on transportation infrastructure. The residents have awarded a mean score of 3.51 to Pressure on Natural Vegetation and Wildlife, which leads to the conclusion that tourism development in natural heritages and 
protected areas are destroying the biological diversity and physical integrity of the destinations.

The mean score of Water Management (3.33) proves that tourist destinations have effective and efficient mechanisms for mitigating pressure on water resources. The mean score of 3.24 for Land Management leads to the conclusion that the destinations have proper land management mechanisms to mitigate the pressure on land due to tourism development. The average score on Management of Transportation (3.38) leads to the conclusion that the government has taken suitable measures to mitigate the pressure on transportation. The local community assigned a mean score of 3.42 to Management of Natural vegetation and wildlife, which proves that the government has introduced various programmes for mitigating the degradation of natural vegetation and loss of wildlife in the natural heritages.

The high mean value of Waste Generation (3.66) leads to the conclusion that tourism activities generate huge amounts of waste in many tourist destinations. The respondents have given a low mean score to Waste Management (3.05), which provides weak support for the argument that the Government has installed efficient and effective waste management systems at various tourist places. The average score of Promoting Energy Conservation (3.03) discloses that the government is not vigorously promoting sustainable utilization of conventional and non-conventional energy. The mean value of 3.21 for Environmental Education substantiates that the government is providing environmental education and awareness to the local community. Similarly, the local community believes that the tourism business operators are also actively contributing to Environment Management (3.34). Thus, the findings from descriptive statistics substantiate the empirical research hypothesis that tourism development is directly contributing to the environmental sustainability of tourist destinations in Goa.

Social Sustainability: The residents have assigned a reasonably high mean score (3.54) to tourism Preserve Sociocultural Heritages because they believe that Goa tourism ensures the protection and conservation of socio-cultural heritages. The average score of Revive Local Festivals (3.39) reveals that tourism promotes and revives local festivals and folklores of the indigenous communities. The variable Commercialization of Culture has recorded a mean score of 3.39, which reveals that tourism development in Goa leads to the commercialization of culture. Similarly, the Cultural Clashes scored a high mean value of 3.51 , which shows that tourism leads to clashes of culture between the tourists and the local community. A high mean score of Anti-Social Activities (3.86) discloses that tourism is invariably responsible for increasing anti-social activities such as crime, drug abuse, alcoholism, prostitution, etc. The average score on Loss of Habitat (3.30) explains that tourism development has led to the loss of habitats to human beings, animals, and natural vegetation. Likewise, the local people have assigned an average score of 3.32 for Bad Influence on Children, which indicates that tourism is adversely affecting the attitude and behaviour of the young generation. Conversely, the Local Community Behaviour has recorded a mean score of 3.48, which establishes that the local community maintains good behaviour and a positive attitude towards tourism development.
The descriptive statistics on social sustainability indicators lead to the conclusion that tourism development raises a big question mark on the social sustainability of Goa tourism. Hence, the findings on social sustainability indicators repudiate the empirical hypothesis that tourism directly contributes to the socio-cultural sustainability of Goa.

\section{Factor Analysis}

This section examines the sustainability of tourism development and identifies the factors, which affect the economic, environmental, and socio-cultural sustainability of Goa from the perspective of the local community using factor analysis. The suitability of data for factor analysis is examined by applying the Keiser-Myer-Olkin test and Bartlett Test of Sphericity. The Keiser-Myer-Olkin test measures the sampling adequacy and Bartlett's test of sphericity examines the null hypothesis that the original correlation matrix is an identity matrix [16]. Table 2 shows the results of the sampling test and data assumptions from Kaiser-Meyer-Olkin (KMO) and Bartlett test of Sphericity.

\begin{tabular}{ll}
\multicolumn{2}{c}{ TABLE II: KMO AND BARTLETT'S TEST } \\
\hline Kaiser-Meyer-Olkin Measure of Sampling Adequacy & .652 \\
Approx. Chi-Square & 894.778 \\
Bartlett's Test of Sphericity & \\
Degree of Freedom & 190 \\
Significance & .000 \\
\hline
\end{tabular}

From the table above Table II, the Bartlett test of Sphericity is statistically significant and rejects the null hypothesis that the original correlation matrix is an identity matrix (Chisquare $=894.778, \mathrm{p}<0.000)$. The Kaiser-Meyer-Olkin (KMO) overall measure of sampling is 0.652 , which indicates that data are suitable for the principal component analysis.

Table III and Fig. 1 represent the results of factor analysis including the factors, eigenvalues, percentage of variance, and percentage of the cumulative variance of initial eigenvalues and rotation sum of squared loadings for 40 variables after performing factor analysis with varimax rotation using Principal Component Analysis (PCA).

TABLE III: TOTAL VARIANCE EXPLAINED FOR EXTRACTED FACTORS

\begin{tabular}{ccccccc}
\hline \multirow{2}{*}{ Factors } & \multicolumn{3}{c}{ Initial Eigenvalues } & \multicolumn{3}{c}{$\begin{array}{c}\text { Rotation Sums of Squared } \\
\text { Loadings }\end{array}$} \\
\cline { 2 - 7 } & Total & $\begin{array}{c}\text { \% of } \\
\text { Variance }\end{array}$ & $\begin{array}{c}\text { Cumulative } \\
\%\end{array}$ & Total & $\begin{array}{c}\text { \% of } \\
\text { Variance }\end{array}$ & $\begin{array}{c}\text { Cumulative } \\
\%\end{array}$ \\
\hline 1 & 3.060 & 15.299 & 15.299 & 3.060 & 15.299 & 15.299 \\
2 & 2.048 & 10.241 & 25.540 & 2.048 & 10.241 & 25.540 \\
3 & 1.721 & 8.603 & 34.143 & 1.721 & 8.603 & 34.143 \\
4 & 1.588 & 7.938 & 42.081 & 1.588 & 7.938 & 42.081 \\
5 & 1.324 & 6.619 & 48.700 & 1.324 & 6.619 & 48.700 \\
6 & 1.253 & 6.266 & 54.966 & 1.253 & 6.266 & 54.966 \\
7 & 1.113 & 5.564 & 60.531 & 1.113 & 5.564 & 60.531 \\
\hline
\end{tabular}

Source: SPSS Output from Primary Survey. 


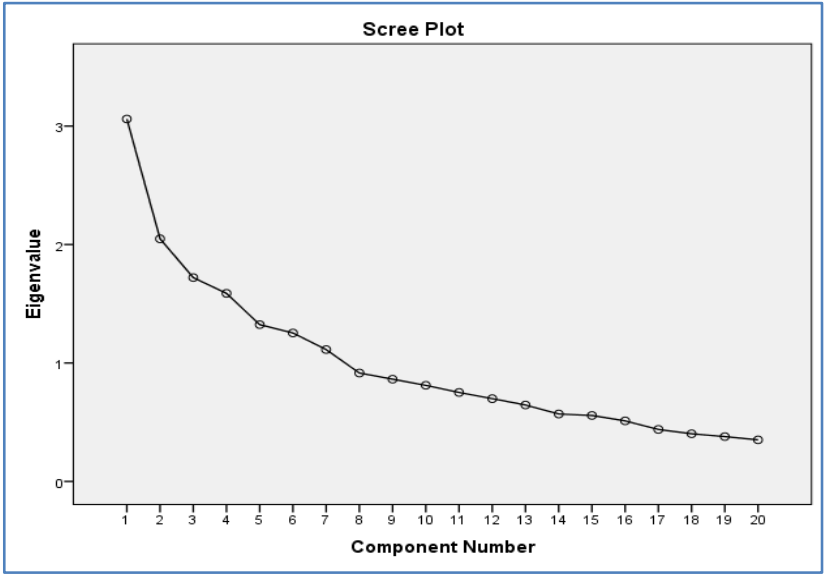

Fig. 1. Scree Plot. Source: SPSS Output from Primary Survey.

Table III and Fig. 1 Scree Plot exhibit the variances and cumulative variances of fourteen factors after performing factor analysis using Principal Component Analysis (PCA). The cumulative variance for the fourteen significant factors is $60.531 \%$ after performing the varimax rotation of factors. The factors extracted from Table III are named as the Resource Exploitation (15.299\%), Resource Management (10.241\%), Socio-economic Empowerment (8.603\%), Economic and Governance Systems (7.938\%), Destination Empowerment (6.619\%), Poverty Eradication (6.266\%) and Tourism Governance $(5.564 \%)$, which explain $60.531 \%$ of the variance in the model.

TABLE IV: ROTATED FACTOR MATRIX

\begin{tabular}{|c|c|c|c|c|c|c|c|}
\hline \multirow{2}{*}{ Variables } & \multicolumn{7}{|c|}{ Factors } \\
\hline & 1 & 2 & 3 & 4 & 5 & 6 & 7 \\
\hline Pressure on Land & .746 & & & & & & \\
\hline Pressure on Natural & & & & & & & \\
\hline $\begin{array}{l}\text { Vegetation and wildlife, } \\
\text { coastal regions }\end{array}$ & .663 & & & & & & \\
\hline Loss of Habitats & .613 & & & & & & \\
\hline Pressure on & 572 & & & & & & \\
\hline Transportation & $.5 / 2$ & & & & & & \\
\hline Pressure on Water & .538 & & & & & & \\
\hline Land Management & & .790 & & & & & \\
\hline Transportation & & 764 & & & & & \\
\hline Management & & .104 & & & & & \\
\hline Water Management & & .602 & & & & & \\
\hline $\begin{array}{l}\text { Protection and Social and } \\
\text { Cultural Heritages }\end{array}$ & & & .777 & & & & \\
\hline Promote Locally Made & & & 600 & & & & \\
\hline Products & & & .099 & & & & \\
\hline Promotion of Homestay & & & 582 & & & & \\
\hline Facilities & & & .582 & & & & \\
\hline Efficient Legal System & & & & .644 & & & \\
\hline Provide Sill Development & & & & 632 & & & \\
\hline Programmes & & & & .032 & & & \\
\hline $\begin{array}{l}\text { Equitable Distribution of } \\
\text { Revenue }\end{array}$ & & & & .575 & & & \\
\hline Women Empowerment & & & & & .834 & & \\
\hline Protects and Revives & & & & & & & \\
\hline Local Festivals and & & & & & .691 & & \\
\hline Folklores & & & & & & & \\
\hline Poverty Reduction & & & & & & .792 & \\
\hline Employment Generation & & & & & & .686 & \\
\hline Local Government & & & & & & & .746 \\
\hline Involvement & & & & & & & .146 \\
\hline Tourism Plans & & & & & & & .635 \\
\hline
\end{tabular}

Source: SPSS Output from Primary Survey.

Note: Table IV shows the results on factor analysis, extraction method based on Principal Component Analysis after Varimax Rotation of principal factors with Kaiser Normalization. Factors 1 to 7 are Resource Exploitation, Resource Management, Socio-economic Empowerment, Economic and Governance Systems, Destination Empowerment, Poverty Eradication, Tourism Governance.
Table IV shows the results from the rotated factor matrix of fourteen factors generated from the factor analysis. The table displays the variables having a factor loading above 0.45 , which indicates the existence of a strong and significant correlation between the variables and the factors.

Table IV shows the results of varimax rotation with Kaiser Normalization, in which 20 significant measured variables out of the initial 40 measured variables are clustered into seven factors based on Eigenvalues. These factors are Resource Exploitation, Resource Management, Socioeconomic Empowerment, Economic and Governance Systems, Destination Empowerment, Poverty Eradication, and Tourism Governance:

1) Resource Exploitation: Resource Exploitation is the most important factor that influences the sustainability of the tourist destination in Goa. The resource exploitation is composed of Pressure on Land (.746), Pressure on Natural Vegetation and Wildlife (.663), Pressure on Transportation (.572), Loss of Habitats (.613), and Pressure on Water (.538). Indiscriminate modern tourism development in Goa has put huge pressure on precious natural resources and manmade resources. The tourism industry and the Goa government have to recognize the critical importance of these resources and introduce integrated programmes for sustainable utilization and conservation of precious natural and sociocultural resources.

2) Resource Management: Resource Management is the second most important factor that contributes to the sustainability of destinations in Goa. The resource management is composed of Transportation Management (.764), Water Management (.602), and Land Management (.790). The local community believes that Goa tourism has adopted suitable strategies for sustainable exploitation and conservation of resources. It has introduced an efficient and effective destination management system to address pressing problems such as transportation bottlenecks, misuse, and misappropriation of land and water resources.

3) Socio-economic Empowerment: Socio-economic empowerment is another major factor, which contributes to the sustainability of tourist destinations in Goa. The socioeconomic empowerment attributes are Promotion of Sociocultural Heritages (.777), Prefer Locally Made Products (.699), and Prefer Homestay Accommodations (.582). The factor analysis reveals that the government and the tourism industry are promoting social and cultural heritages, indigenously made products, and homestay accommodation facilities.

4) Economic and Governance System: The factor analysis explains that the Economic and Governance System influences the sustainability of tourist destinations in Goa. An Efficient Legal System (.644), Skill Development Programme (.716) and Equitable Distribution of Revenue (.575) are the constituents of the Economic and Governance System. Adequate security arrangements have been provided by the government at all destinations for ensuring the safety and security of tourists. The government and private agencies and institutions provide various training and skill development programmes for developing human resources required for the tourism industry. It has also installed an efficient and effective legal system to deal with the violation of tourism-related rules and regulations. Tourism also ensures 
that revenue generated by tourism is equitably distributed across the population.

5) Destination Empowerment: Destination Empowerment is an important factor that contributes to the economic and social sustainability of tourist destinations of Goa. The Empowerment of Women (.833) and Revive Local Festivals and Folklores (.691) are the favourable impacts of tourism. Tourism provides direct and indirect employment opportunities to women and vulnerable sections of society. Tourism helps to revive and conserve the indigenous cultural heritages. Goa is commercially exploiting indigenous culture, traditions, and cuisines, which provides opportunities to local communities to earn a livelihood from the performance of traditional art forms and folklores.

6) Poverty Eradication: The factor analysis establishes that poverty eradication is an important factor, which directly contributes to the sustainable economic development of Goa. The high factor loading on Poverty Reduction (.792) signifies that tourism is instrumental in the economic empowerment of the local community through the eradication of poverty. The high factor loading of Employment Generation (.686) reveals that tourism is an important segment of the economy, which generates employment opportunities directly and indirectly.

7) Tourism Governance: The factor analysis discloses that Tourism Governance is a significant factor that leads to the sustainable development of Goa. Tourism Plans (.635) and Local Government Engagement (.746) are integral components of tourism governance. The meticulously designed and implemented national tourism policy and state tourism programmes and strategies supported by necessary legislation and regulations provide the right direction to sustainable tourism development in the state.

\section{CONCLUSION}

The main objective of this section was to examine the economic, environmental, and social sustainability of Goa tourism from the perspective of the local community. The descriptive statistics establish that tourism leads to the economic and environmental sustainability of the destinations. However, the findings do not support the hypothesis that tourism leads to the sustainable development of the social environment. The factor analysis discloses that the factors such as resource exploitation, resource management, socio-economic empowerment, destination empowerment, employment generation, poverty eradication, socio-environmental impacts, economic and governance systems, legal and financial environment, waste disposal management, conservation of the environment, tourism governance, local community empowerment, and environmental degradation, influence the sustainability of tourism in Goa.

\section{Limitations of the Research and Directions for Future Research:}

This research paper has certain limitations. This paper could not incorporate the opinion of tourists, tourism business operators, and Government agencies, and Non-Governmental Organizations (NGOs) because of the time constraints and seasonal nature of tourism in Goa. As the database created for examining the sustainability of Goa tourism is based on judgmental sampling and random sampling, the findings from this research project may be subjected to the limitations of both sampling methods. An important extension of this research would be to examine the economic, environmental, and socio-cultural sustainability from the perspectives of the different stakeholders such as tourists, local community, tourism business, government agencies, and NGOs. The research should attempt to broaden the sample size and adopt more rigorous research methods for empirically testing and validating the sustainability of tourism development.

\section{ACKNOWLEDGEMENT}

This research paper is one of the outcomes of the research project titled "Sustainable Tourism Development in India: A Case Study of Goa Tourism" which was funded by the Indian Council of Social Sciences Research (ICSSR), New Delhi, India.

\section{REFERENCES}

[1] Wilson, D. (1997). Paradoxes of Tourism in Goa, Annals of Tourism Research, 21 (1), pp. 52-75.

[2] Brammer, N., \& Beech, J. (2004). Use and Abuse of Tourism: the Goan Experience, Tourism, Culture \& Communication, 5, pp. 23-35.

[3] UNEP \& UNWTO. (2005). Making Tourism More Sustainable, A Guide for Policy Makers, http://www.worldtoourism.org.

[4] Swarkar, K., Naronia, L., Mascarenhas, A., \& Chauhan, O. S. (1998). Tourism and the Environment: Issues of Concerning the Coastal Zone of Goa, The International Bank for Reconstruction and Development, The World Bank, pp. 1-19.

[5] Solomon, R. (2009). The Challenges and Prospects of Tourism in Goa Today, Council for Social Justice and Peace, Goa, pp. 1-100.

[6] Thomas, R., Gareth, S., \& Page, S. J. (2011). Understanding Small Firms in Tourism: A Perspective on Research Trends and Challenges, Tourism Management, 32, pp. 963-976.

[7] Gama, D. A., \& Solomon, R. (2011). Reclaiming Water Rights: Towards an Equitable Social Contract in Goa, Water Equity in Tourism (WET) program, Centre for Responsible Tourism, Goa and Tourism Concern, UK, pp. 1-70.

[8] Menon, K. A. G. (1993). Case Study on the Effects of Tourism on Culture and Environment India, Jaisalmer, Khajuraho and Goa, UNESCO, Principal Regional Office for Asia and the Pacific, Bangkok, pp. 1-114.

[9] KPMG and Department of Goa Tourism. (2016). Tourism and Hospitality: Achievements.

[10] Solomon, R. (2011). The Challenges and Prospects of Tourism in Goa Today, Council for Social Justice and Peace, Goa, pp. 1-100.

[11] Alvares, C. (1993), "Fish, Curry, and Rice: A Citizen's Report on the State of the Goan Environment." Ecoforum. Goa, pp. 260.

[12] Ahmed, Sheik Ali \& Shankar, B. (2012). Guidelines for Regulating the Heritage Monuments and Areas in Old Goa, International Journal of Modern Engineering Research, 2(6), pp.4732-4735. Fellario (2015).

[13] Vellas, François. (2011). The Indirect Impact of Tourism: An Economic Analysis, Toulouse University - TED AFL, Third Meeting of T20 Tourism Ministers Paris, France.

[14] NWTO. (2017). Sustainable Development Goals. https://www.unwto.org/sustainable-development.

[15] Venugopalan, T., \& Dharmendra, Kumar. (2017). Sustainable Development through Sustainable Tourism: A Case Study of Kerala Tourism. Asian Journal of Research in Business Economics and Management, 7(12), pp.10-17.

[16] Hair, J.F., Black, W. C., Babin, B.J, \& Anderson, R.E, (2019) Multivariate Data Analysis, 8th ed., Cengage, New Delhi.

[17] Noronha, L., Lourenco, N., Lobo-Ferreira, J.P., Lleopart, A., Feoli, E., Sawarkar, K. \& Chachadi, A. (2002). Coastal Tourism, Environment, and Sustainable Local Development, TERI, New Delhi, pp. 1-51, www.teriin.org.

[18] Sustainable Tourism for India Criteria and Indicators, Applicable to Accommodation Sector and Tour Operators. (2011). Ministry of Tourism, Government of India. http://www.incredibleindia.org. 


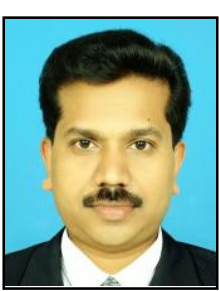

Dr Venugopalan $\mathbf{T}$ is an assistant professor in the Department of Commerce, Sri Guru Tegh Bahadur Khalsa College, University of Delhi, India. He received his Master's degree from the University of Calicut, Kerala, and his PhD. from the Faculty of Management Studies (FMS), University of Delhi. His area of specialisation is Accounting and Finance. 